\title{
How can we Detect the Balance System Disorder and its Improvement after Rehabilitation?
}

\author{
Ágnes Szirmai*, Stefani Maihoub, András Molnár and László Tamás \\ Department of Oto-Rhino-Laryngology, Head and Neck Surgery, Faculty of Medicine, Semmelweis University, Hungary
}

Received: May 30, 2018; Published: June 12, 2018

*Corresponding author: Ágnes Szirmai, Department of Oto-Rhino-Laryngology and Head and Neck Surgery, Faculty of Medicine, Semmelweis University, Budapest, Hungary

Keywords: Vestibular; Vertigo; Vasoactive Drugs; Vinpocetine; Piracetam; Post Traumatic; Electronystagmography; Neurotological; Statokinetic; Cerebrovascular Disorder

Abbreviations: VRT: Vestibular Rehabilitation Therapy; CCG: Craniocorpography; CMS: Coordinate Measurement System®; US-COMP-CCG: Ultrasound-Computer-Craniocorpography; DHI: Dizziness Handicap Inventory

\section{Introduction}

Physicians are found to have a great and increasing amount of patients suffering from vertigo in their everyday practice. For the treatment of the balance disorders, a vestibular training was introduced which played an influential role based on our study. Rehabilitation of patients having balance disorders is a known, major challenge for physicians. Vestibular rehabilitation therapy (VRT) is an exercise-based treatment program designed to promote vestibular adaptation and substitution. The goals of VRT are

1) to enhance gaze stability.

2) to enhance postural stability.

3) to improve vertigo.

4) to improve activities of daily living.

According to our clinical experiences, combination of medical treatment with vestibular training is beneficial for every vestibular disorder. The medical treatment modalities consist of vasoactive drugs (e.g. vinpocetine, piracetam) in chronic vestibular disorders. Authors demonstrated that vestibular physical rehabilitation therapeutic strategies produced improvement in different vestibular disorders, e.g. post-traumatic and migrainous vertigo.

Objectives: The objective is to show the usefulness of ultrasound-computer-craniocorpography in registration of balance disorders and to show effectiveness of the vestibular rehabilitation training.

\section{Methods}

For establishing necessary topodiagnostic procedure we are using a special neurotological history scheme, the computer based electronystagmography with caloric and optokinetic tests. Vestibular spinal testing is objectively recorded through craniocorpography (CCG). Craniocorpography was designed firstly as a non-electronic, simple office recording procedure for head and body movements. The regular craniocorpography procedure combines a stepping test (Unterberger, Fukuda) with a standing test (Romberg). Through a local positioning system a very precise localization of ultrasound markers is possible. Sound is moving through air with an average velocity of $330 \mathrm{~m}$ per sec. By means of 3 microphones in fixed arrangement in space the sound signal can be precisely located according to its source. This is based on a mathematical analysis. This principle is installed into the ZEBRIS Coordinate Measurement System ${ }^{\circledR}$ (CMS). For analyzing headand body movements under the strain of different test profiles we apply the following voluntary tests which must be performed by the patient when being instructed by an investigator. The PC contains a program, which releases impulses of ultrasound through the markers of the test person. It also arranges the collection of the sound signals from the microphones. The patient is carrying a helmet with two ultrasound markers and a shoulder fixation with two other ultrasound markers. A computer unit is triggering the ultrasound impulses. Further back from and above the patient is the ultrasound receiver unit, containing several ultrasound 
microphones and data processors receiving the sound traces from the head and from the shoulders. The signals received are triggered by as well as sent to the computer unit. The computer unit calculates the spatial position of all the four ultrasound markers. The PC software shows the results obtained in each test online. Using ultrasound-markers on head and shoulders the computer can measure and analyze the numerical data of statokinetic tests of the patients suffering of vertigo or balance disorders. The UltrasoundComputer-Craniocorpography (US-COMP-CCG), developed by Claussen, is a simple, reliable, quantifiable and reproducible method for statokinetic test investigation of vertigo victims. It consists of optically monitoring the patient's head and body movements as they perform the classical Romberg's and Unterberger's tests. Our experiences show that ultrasound-computer-craniocorpography is useful test in the examination of the vertiginous population.

\section{Case history}

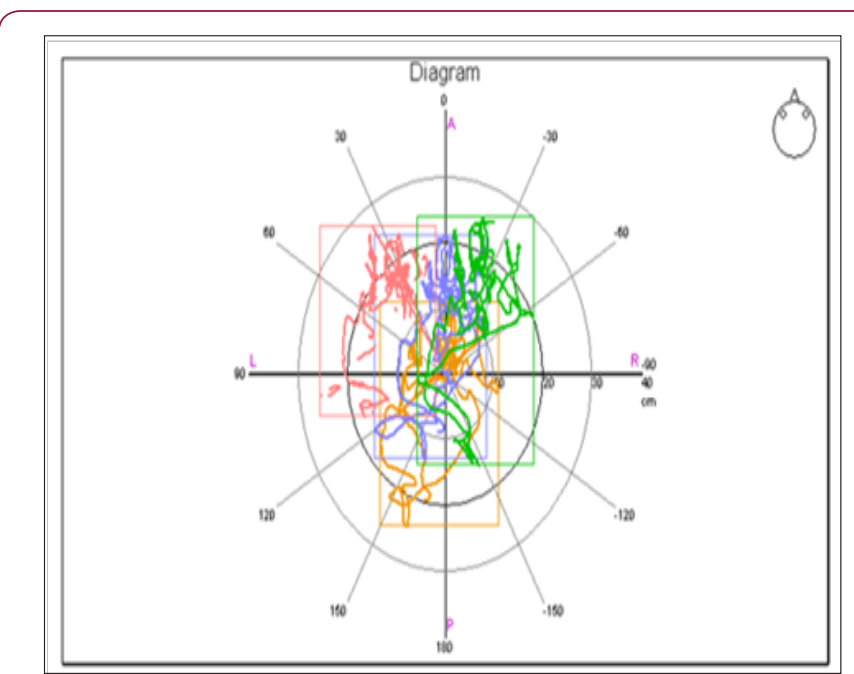

Figure 1: Registration of Romberg Test before Treatmentby US-COMP-CCG.

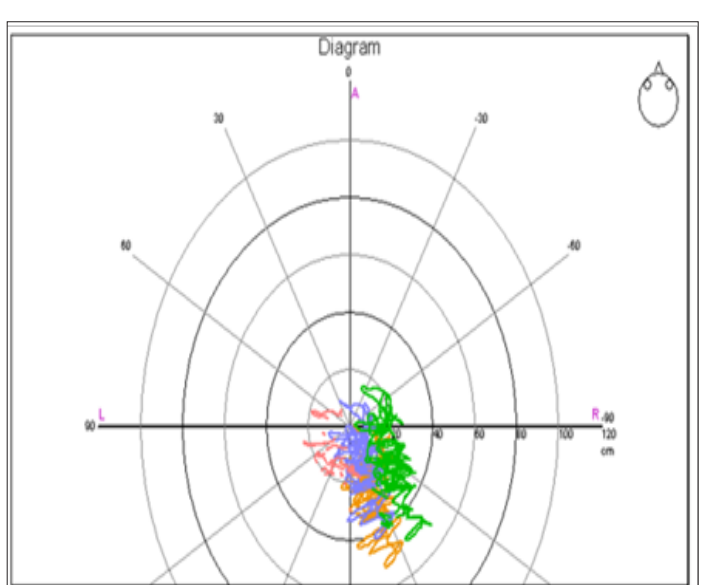

Figure 2: Registration of Unterberger -Fukuda Test before Treatmentby US-COM-CCG.

Mrs. SZ.L. is a 68 years old female, who has been suffering from central vestibular lesion more than a year due to cerebrovascular disorder. Ten days long vasoactive treatment and vestibular rehabilitation training was performed during her hospitalization. During the treatment her stability improved, and the DHI (dizziness handicap inventory) score, which was 56 points at the beginning of treatment, decreased to 28 points, showing that the severe deterioration in quality of life of patient improved to a mild deterioration. The figures illustrate the decreased imbalance after the combined treatment, registered by ultrasound-computercraniocorpography in both of the statokinetic tests (Figures 1-4).

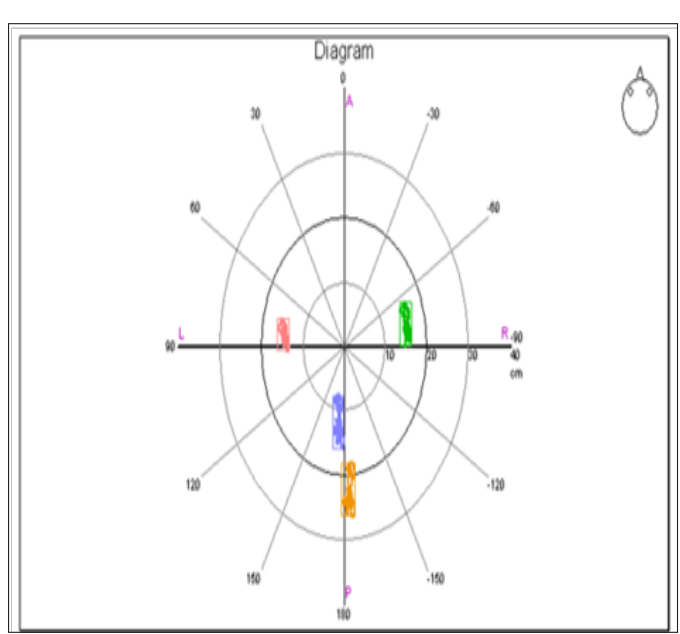

Figure 3: Registration of Romberg Test after Treatmentby US-COMP-CCG.

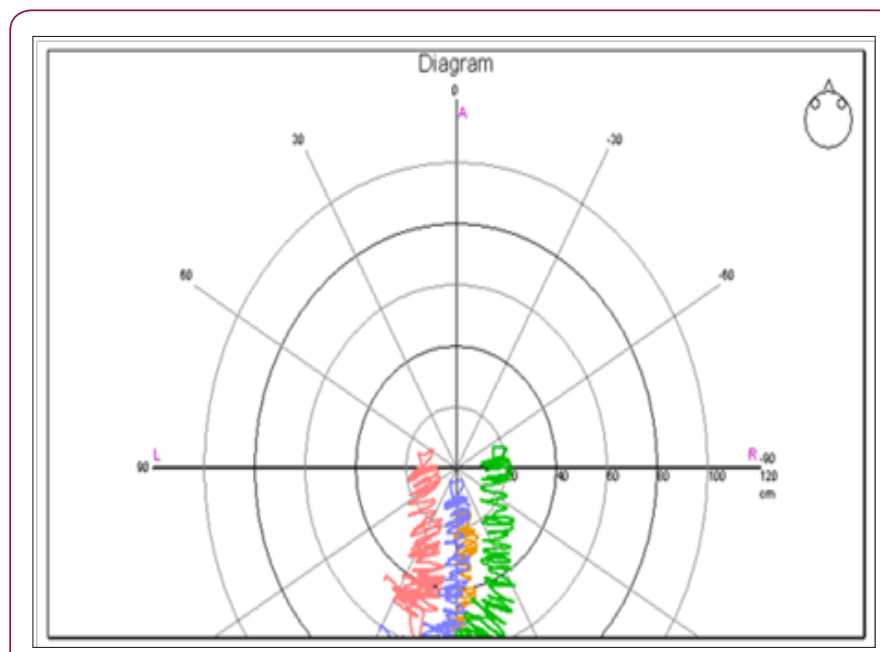

Figure 4: Registration of Unterberger-Fukuda Test after Treatment by US-COMP-CCG.

\section{Conclusion}

With the appliance of neurotological examinations and the assistance of ultrasound-computer-craniocorpography, we are able to exhibit objectively the existence of vestibular disorder and detect the improvement after the suggested combined therapy.

\section{References}

1. Gottshall, KR, Moore RJ, Hoffer ME (2005) Vestibular rehabilitation for migraine-associated dizziness. Int Tinnitus J11(1):81-84.

2. Szirmai A, Maihoub S, Tamás L (2018) Efficacy of assisted balance training in chronic vestibular vertigo Az asszisztált egyensúlyi tréning 
hatékonysága krónikus vestibularis rendszeri szédülésben Orv Hetil 159(12): 470-477.

3. Szirmai A, Maihoub S, Tamás L (2014) Usefulness of ultrasoundcomputer-craniocorpography in different vestibular disorders. Int Tinnitus J 19(1):6-9.

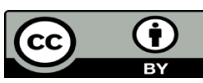

This work is licensed under Creative Commons Attribution 4.0 License

Submission Link: https://biomedres.us/submit-manuscript.php
4. Jacobson GP, Newman CW (1990) The development of the Dizziness Handicap Inventory. Arch Otolaryngol Head Neck Surg. 116(4): 424-427.

AIOMEDICAL
RESEARCHES $\quad \begin{aligned} & \text { Assets of Publishing with us } \\ & \text { - Immal archiving of articles }\end{aligned}$

